\title{
HPLC determination of Ursolic acid in flowers of an Iranian Pomegranate (Punica granatum L.) Cultivar
}

\author{
Research Article
}

\section{Sharifiyan Fatemeh ${ }^{1 *}$, Mirjalili Seyed Abbas ${ }^{2}$, Fazilati Mohammad ${ }^{1}$, Habibollahi Saeed ${ }^{3}$, Poorazizi Elahe ${ }^{4}$}

\author{
1. Department of Biology, Payame Noor University (PNU), Iran, 2. Imam Khomeini Higher Education Center, \\ Agricultural Research, Education and Extension Organization(AREEO), Tehran, Iran \\ 3. Department of Chemistry, Payame Noor University (PNU), Iran \\ 4. Najafabad Branch, Islamic Azad University, Isfahan, Iran
}

\begin{abstract}
Ursolic acid (UA), is a major bioactive compound in several traditional medicinal plants including pomegranate (Punica granatum L.) flower. This study presents the HPLC analysis of UA content in flowers of an Iranian pomegranate cultivar. The analytical method's accuracy and the repeatability were satisfactory. The Linear ranges were $100-400 \mu \mathrm{g} / \mathrm{ml}$ for UA with a good correlation. On the average, the recovery rate of UA was $100 \%$. Here, the extraction of UA from an Iranian pomegranate flower cultivar by employing an ultrasound-assisted extraction method was reported, and several extraction solvents were studied to improve extraction yield of UA. Remarkable quantities of UA were found in cultivar of pomegranate flower evaluated. Our results showed that Iranian pomegranate flower cv. Ghorj Tafti Torsh is a good source for extraction and isolation of UA.
\end{abstract}

Keywords: HPLC, Pomegranate flowers, Ursolic acid.

\section{Introduction}

Punica granatum Linn. (Punicaceae), commonly known as pomegranate, is an important commercial fruit crop, extensively cultivated in the Middle East, North Africa, the Mediterranean and in parts of Asia (Tehranifar et al. 2010). The plant possesses an immense therapeutic value. Pomegranate flowers have been widely used in Ayurvedic, Unani and Chinese medicine systems (Mirjalili 2015). The flowers are strongly astringent and a unique traditional antidiabetic medicine. A decoction of pomegranate flowers stops bleeding and treats tympanitis. The flowers are also used in traditional Chinese medicine to treat injuries from falls, to cure graying hair in young men and to treat chronic diarrhea, especially in children (Kaur et al. 2006; Amjad et al. 2013). Pomegranate flowers contain multiple secondary metabolites, the most abundant of which are polyphenols such as ellagic acid, gallic acid and ethyl brevifolin-carboxylate; and triterpenes including ursolic, oleanolic, maslinic and asiatic acids. These compounds have shown strong medicinal values and biological activities (zhang et al. 2011). As an ursane-type pentacyclic triterpene, Ursolic acid (UA, $3 \beta$-hydroxy-12-urs-12-ene-28-oic acid) (Fig. 1) is a

\footnotetext{
*Corresponding Author:

Sharifiyan Fatemeh

Department of Biology,

Payame Noor University (PNU),

IRAN
}

Email: fate.sharifiyan@yahoo.com constituent of some medicinal plants. UA also forms the main part of protective coatings of different fruits including apple, pear, olive, prune, cranberry and fig (Rao et al. 2011; Chen et al. 2015). For a long time, UA was thought not to be active biologically, while in recent years, because of its pharmacological effects and low toxicity, it has attracted a lot of attention (Ikeda et al. 2008). UA possesses considerable pharmacological effects including hepatoprotective (Saravanan et al. 2006; Jin et al. 2012), immunomodulatory (Saaby et al. 2011), anti-inflammatory (Ali et al. 2007; Zhang et al. 2013), antidiabetic (Wang et al. 2008; Perez Gutierrez et al. 2009), antitumor (suhagia et al. 2013), antibacterial (Kurek et al. 2012; do Nascimento et al. 2013), antiviral (Wu et al. 2011; Kong et al. 2013), antiulcer (Ishikawa et al. 2008) and anticancer activities (Shanmugam et al. 2013). UA has recently attracted increasing attention due to its multifunctional anticancer activities (Shanmugam et al. 2013; Yang et al. 2013). Anti-inflammatory and anti-proliferative, proapoptotic, anti-metastatic and anti-angiogenic ability of UA have been reported in both in vitro and in vivo models of cancer (Shao et al. 2011; Shanmugam et al. 2013).

This study aimed to identify and quantify UA in Iranian pomegranate flowers cv. Ghorj Tafti Torsh by HPLC, for better nutritive evaluation and medicinal utilization in the future. Here, an ultrasound-assisted extraction method was employed to extract UA from pomegranate flowers and several extraction solvents were studied in an attempt to improve extraction of UA from pomegranate flowers. 


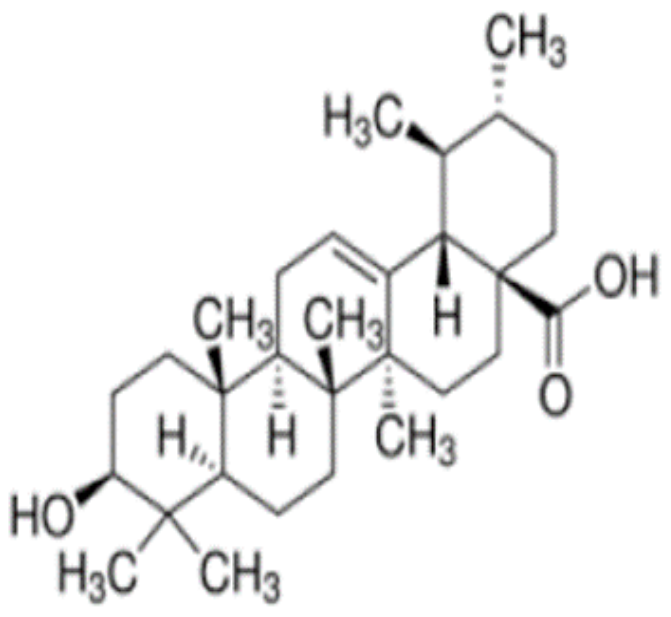

Fig.1 Structure of Ursolic acid (UA, 3 $\beta$-hydroxy-12-urs -12-ene-28-oic acid)

\section{Materials and Methods}

Chemicals

Ursolic acid standard (European Pharmacopoeia Reference Standard) was purchased from Sigma-Aldrich to control biological and pharmaceutical products. Methanol (HPLC grade) was bought from Merck (Germany) and pure water was utilized to HPLC analysis. Analytical grade Ethanol and Ethyl acetate were purchased from Merck (Germany).

\section{Preparation of standard solution}

Stock standard solution of UA was prepared by solving an adequate amount of UA in methanol to obtain an ultimate concentration of $1 \mathrm{mg} / \mathrm{mL}$. A serial dilution was made with methanol to prepare standard solutions at concentrations of $100,200,300$ and $400 \mu \mathrm{g} / \mathrm{mL}$, from each of which $20 \mu \mathrm{L}$ was utilized to plot a standard curve for UA.

\section{High-performance liquid chromatography system}

HPLC was performed on a SY-8100 system equipped with SY-8100 HPLC pump, a 7725i manual sample injector, a variable-wavelength UV detector, and SY-8000 HPLC software. The analytical column, which was used, was Venusil MP C18 $(250 \mathrm{~mm} \times 4.6 \mathrm{~mm}, 5$ $\mu \mathrm{m})$. The mobile phase was composed of methanol and $0.1 \mathrm{M}$ Phosphate buffer $(\mathrm{PH}=3,90: 10)$. The flow rate was $0.9 \mathrm{~mL}$ min-1 and elute was monitored at $210 \mathrm{~nm}$. The column temperature was kept fixed at $21 \pm 1^{\circ} \mathrm{C}$.

\section{Preparation of sample solution}

Pomegranate flowers were collected in May 2016 from cv. Ghorj Tafti Torsh pomegranate trees growing in the Pomegranate Genetical Garden Collection in Isfahan Province, Iran. The perfect flowers were dried at $105^{\circ} \mathrm{C}$ for $15 \mathrm{~min}$, and then at $65^{\circ} \mathrm{C}$ in a hot-air oven for 2 days.

Extracts from pomegranate flowers were prepared using $90 \%$ ethanol, ethyl acetate and ethyl acetate followed by $90 \%$ ethanol as solvents in order to determine the optimum extraction solvents of UA.

One gram of pomegranate flower powder was dissolved in $20 \mathrm{~mL}$ solvent followed by $50 \mathrm{~min}$ ultrasonic extraction at $40^{\circ} \mathrm{C}$ by $\mathrm{MH} \mathrm{S3}$ ultrasonic machine (Soltec Co. Milan, Italy). For HPLC analysis, the extracts were passed through a $0.45 \mu \mathrm{m}$ membrane filter.

\section{Recovery}

To test the extraction recovery, dried plant powder $(1 \mathrm{~g})$ was added with $2 \mathrm{mg}$ UA standard before extraction. Follow-up extraction along with HPLC analysis was performed as mentioned above in detail. The assessment of the recovery was as follows:

Recovery $(\%)=(\mathrm{A}-\mathrm{B}) / \mathrm{C} \times 100$

Where, $\mathrm{A}$ is the result after adding standard, $\mathrm{B}$ denotes the amount of sample before adding standard, and $\mathrm{C}$ is the amount of added standard.

\section{Repeatability and precision}

To assess the intra-day precision of the method, 200,300 and $400 \mu \mathrm{g} / \mathrm{mL}$ standard solutions of UA were injected several times $(n=5)$ during the same day. These studies were repeated on different days $(n=5)$ in order to assess the inter-day precision.

\section{Results and discussion \\ HPLC conditions}

Because there are no chromophore moieties in Triterpenoids' chemical structures, they indicate poor UV absorption, which is the main limitation in analyzing this group of compounds by employing UV detection. In some cases, in order to detect at higher wavelengths, derivation has been employed (Maurya et al. 2012); however, this extra step may lead to significant errors in the method. In this study, the detection wavelength was chosen at $210 \mathrm{~nm}$ for UA because at this wavelength, it has better absorption and sensitivity.

Based on methanol, acetonitrile, phosphate buffer and phosphoric acid several mobile phases were carefully tested in order to determine better separation and peak shapes. At last, the mobile phase consisting of methanol (A) and phosphate buffer $(\mathrm{PH}=3)(\mathrm{B})$ with a ratio of 90:10 $(\mathrm{A}: \mathrm{B}, \mathrm{v} / \mathrm{v})$ was chosen. It was found that simply by using methanol separation was unsatisfactory, but as an organic modifier with a phosphate buffer solution $(\mathrm{pH}=3)$, methanol performed well. In this regard, adding phosphate buffer improved the separation and peak shapes by controlling $\mathrm{pH}$ with no ion pairing for acidic compounds. $0.9 \mathrm{~mL} \mathrm{~min}-1$ of flow rate was found appropriate to shorten the run time with no compromise for the peak resolution. $21 \pm 1{ }^{\circ} \mathrm{C}$ of controlled column temperature was needed to get reproducible results.

Under these HPLC conditions, the retention time was $9 / 20$ min for UA. HPLC chromatograms of UA standard and the pomegranate flower extract are shown in Figs. 2 and 3, indicating that UA in the pomegranate flower was successfully separated and identified. 
Fig.2 HPLC chromatogram of UA standard

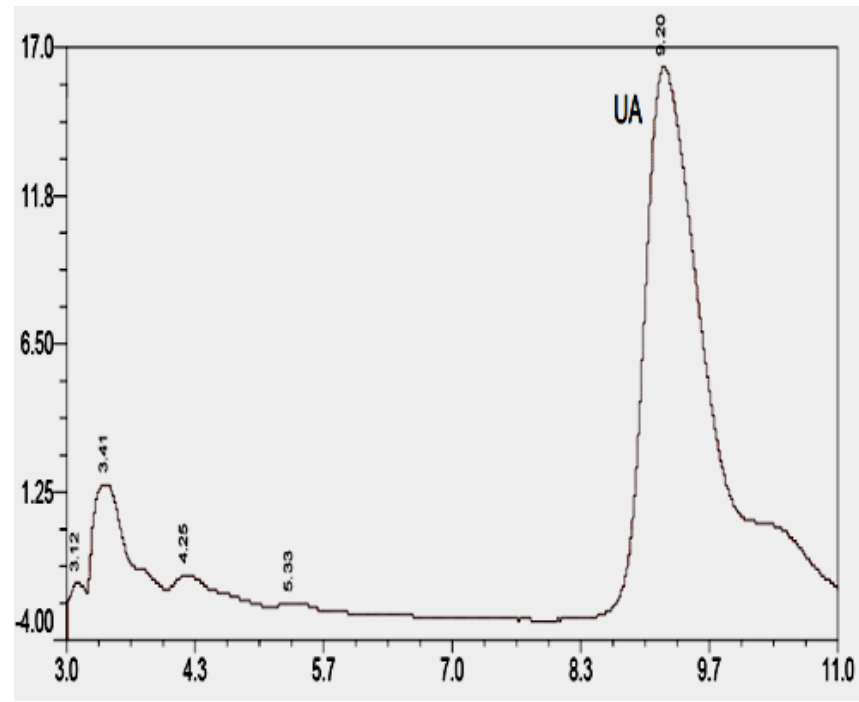

Fig.3 HPLC chromatogram of the pomegranate flower extract

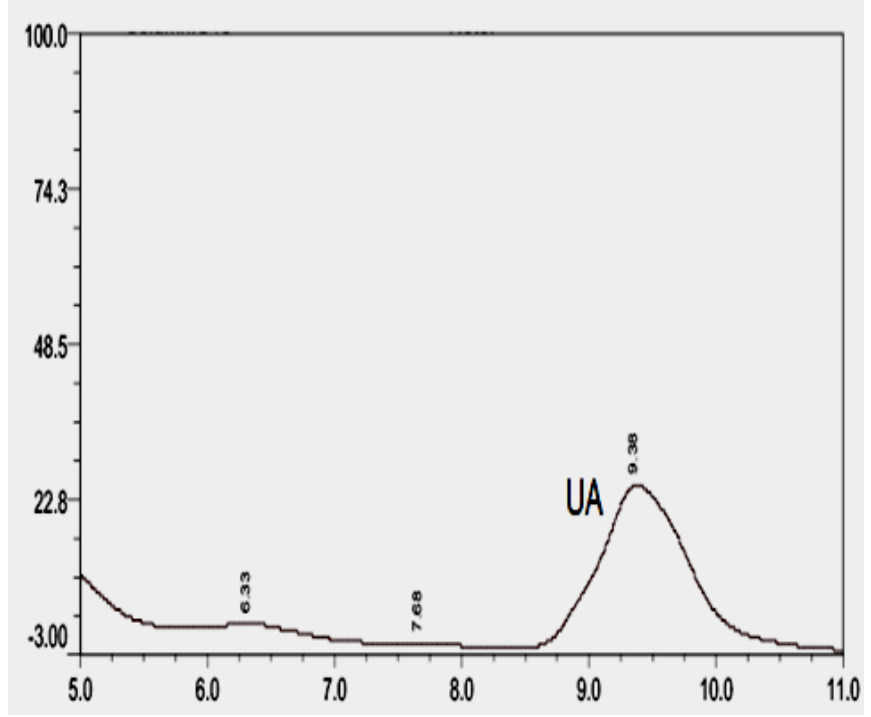

In this part, the effect of different solvents including $90 \%$ ethanol, ethyl acetate and ethyl acetate followed by $90 \%$ ethanol on the extraction yield of UA was evaluated. Fu et al. (2014) showed that ethanol and chloroform are the most effective solvents for the extraction yield of UA in pomegranate flowers. Afterwards, the highest yield of UA was obtained with acetone and ethyl acetate. Most organic solvents (methanol, chloroform and acetone) are toxic (Bernatoniene et al. 2016); therefore, for the extraction of UA, ethanol and ethyl acetate were chosen as solvents. However, Fan et al. (2012) in their study reported that the solubility of UA in pure ethanol solvent is higher than that in mixed solvents (ethanol + water). but, the existence of some water in ethanol could increase the process of mass transfer with an increase in the polarity of the solvent; thus, improving solubilizing capacity of the solvent and also increase the contact surface for solute solvent interaction by efficient swelling in the plant material (Mandal et al. 2010).
Therefore, the water content in the mixed solvents should be as low as possible in order to increase the solubility of UA (in our study $90 \%$ ethanol).

Other extraction parameters were as follows: liquid: material ratio, $20: 1(\mathrm{ml} / \mathrm{g})$ followed by $50 \mathrm{~min}$ ultrasonic extraction at $40^{\circ} \mathrm{C}$. Ultrasound, On the one hand, can produce mechanical action and cavitation in the extraction process, which is efficient in the breakdown of plant cell walls so that the active ingredients are present in a free state and are dissolved in the extraction solvent. On the other hand, Ultrasound can accelerate the movement of molecules, and cause the extraction solvent and active ingredients of plants to contact quickly and combine with each other (Mandal et al., 2010).

The content of UA in various extractions of pomegranate flowers cv. Ghorj Tafti Torsh determined by HPLC has been shown in table 1 . The results showed that higher yields were obtained when $90 \%$ Ethanol or Ethyl acetate was used individually as solvents. Statistically, there were no significant differences in the yields of UA when 90\% ethanol, compared to that when ethyl acetate was used, as the solvent $(\mathrm{P}>0.05)$.

\section{Table 1: Effect of different solvents on the}

\begin{tabular}{|l|l|}
\hline Solvent & Extraction Yield of \\
\hline $90 \%$ Ethanol & $19.044 \pm 0.231$ \\
\hline Ethyl acetate & $19.813 \pm 0.953$ \\
\hline Ethyl acetate $+90 \%$ & $16.886 \pm 1.332$ \\
\hline Data are means $(\mathrm{n}=3) \pm$ standard deviation \\
\hline
\end{tabular}

The pomegranate flowers cv. Ghorj Tafti Torsh had higher UA contents compared to yields from Ligustrum lucidum Ait. (9.8 mg/g) (Xia et al. 2011), Eriobotrya japonica Lindl.(5.6 mg/g) (Xu et al. 2012), Rosmarinus officinalis leaves $(15.8 \mathrm{mg} / \mathrm{g}$ ) (Bernatoniene et al. 2016) and Ziziphora clinopodioides Lam.(1.176 $\mathrm{mg} / \mathrm{g}$ ) (Tian et al. 2010). Jager et al. (2009) quantified the triterpene content of 39 plant materials. They determined maximum concentration of UA in Malus domestica peels (14.3 mg/g), Lavandula angustifolia leaves (15.9 mg/g), Coffea arabica leaves (18 mg/g), Salvia officinalis leaves (18 $\mathrm{mg} / \mathrm{g})$ and Rosmarinus officinalis leaves $(29.5 \mathrm{mg} / \mathrm{g})$. Although UA is present in a wide variety of plants, our results showed that Iranian pomegranate flower cv. Ghorj Tafti Torsh is also a good source of UA.

The extraction yield of UA by the proposed method was also higher than the yields that $\mathrm{Fu}$ et al. (2014) obtained from pomegranate flowers $(12.59 \mathrm{mg} /$ g). This difference could be due to the nature of cultivar of Iranian pomegranate used, and is probably related to environmental effects. The chemical composition and the concentration of active ingredients of a plant could vary considerably depending on soil, water supply, light, the time when it is harvested and environmental cultivations. 
Linearity

The linearity of the responses from the detector was studied for standard substance by plotting peak areas against the amounts, which were injected. There was good agreement between the peak area and the standard amounts at the range of $100-400 \mu \mathrm{g} / \mathrm{ml}$ for UA. The regression equation and coefficient of determination was $[\mathrm{y}=0.0006 \mathrm{x}+18.142](\mathrm{R} 2=$ 0.9955 ) for UA.

\section{Repeatability and precision}

The inter-day and intra-day variations for the determination of UA were less than $3 \%$ at concentrations of 200,300 and $400 \mu \mathrm{g} / \mathrm{ml}$ (Table 2). The low value of $\%$ RSD shows the high accuracy of the method.

\begin{tabular}{|c|c|c|}
\hline \multicolumn{3}{|c|}{ Table 2: Inter-day and intra-day precision for } \\
UA. \\
\hline \multirow{2}{*}{$\begin{array}{c}\text { Concentration } \\
\text { RSD\% }(\mu \mathrm{g} / \mathrm{ml})\end{array}$} & \multicolumn{2}{|c|}{ RSD $\%$} \\
\cline { 2 - 3 } & Intra-day $(\mathrm{n}=5)$ & Inter-day $(\mathrm{n}=5)$ \\
\hline 200 & 2.21 & 1.56 \\
\hline 300 & 1.99 & 1.63 \\
\hline 400 & 1.51 & 2.13 \\
\hline
\end{tabular}

Recovery

By mixing an appropriate amount of quantified samples with the standard compound, recovery experiment was conducted in order to confirm that the method was accurate. The average recovery of UA was $100 \%$.

\section{Conclusion}

In the present study, a simple, accurate and precise HPLC method was developed for the quantification of ursolic acid in flowers of pomegranate. This method is isocratic, and it has an uncomplicated mobile phase; moreover, the preparation of the samples and evaluation procedures are quick and simple.

This study was the first report on the UA content of an Iranian pomegranate flower cultivar. In addition to plant materials supplying a high concentration of UA, the determination of UA in Iranian pomegranate flower cv. Ghorj Tafti Torsh has resulted in the identification of another plant material rich in UA (with concentrations over $1.9 \%$ in the dry plant material).

\section{Acknowledgements}

The authors would like to thank Payame Noor University of Iran for financially supporting this research. We greatly thank Agriculture And Natural Resources Research Center, Amir Hamzeh, Isfahan, Iran, for providing and authenticating the plant materials used in this study.

\section{Disclosure statement}

The authors declare that there are no conflicts of interests.

\section{References}

1. Ali MS, Ibrahim SA, Jalil S, Choudhary MI. 2007. Ursolic acid: a potent inhibitor of superoxides produced in the cellular system. Phytother Res 21: 558-561.

2. Amjad L, Shafighi M. 2013. Evaluation of Antioxidant Activity, Phenolic and Flavonoid Content in Punica granatum var. Isfahan Malas Flowers. Int J Agri Crop Sci 5: 1133-1139.

3. Bernatoniene J, Cizauskaite U, Ivanauskas L, Jakstas V, Kalveniene Z, Kopustinskiene DM. 2016. Novel approaches to optimize extraction processes of ursolic, oleanolic and rosmarinic acids from Rosmarinus officinalis leaves. Ind Crop Prod 84: 72 -79 .

4. Chen H, Gao Y, Wang A, Zhou X, Zheng Y, Zhou J. 2015. Evolution in medicinal Chemistry of ursolic acid derivatives as anticancer agents. Eur J Med Chem 92: 648-655.

5. do Nascimento PG, Lemos TL, Bizerra A, Arriaga $\hat{A}$, Ferreira DA, Santiago GM, Braz-Filho R, Costa JG. 2013. Antibacterial and antioxidant activities of ursolic acid and derivatives. Molecules 19: 13171327.

6. Fan JP, Kong T, Zhang XH, Zhang L, Tong SH, Tian ZY, Zhu JH. 2012. Solubilities of oleanolic acid and ursolic acid in (ethanol + water) mixed solvents from $\mathrm{T}=(292.2$ to 328.2$) \mathrm{K}$. J Chem Thermodyn 47: 372-375.

7. Fu Q, Zhang L, Cheng N, Jia M, Zhang Y. 2014. Extraction optimization of oleanolic and ursolic acids from pomegranate (Punica granatum L.) flowers. Food Bioprod Process 9: 321-3.

8. Perez Gutiérrez RM, Solis RV, Baez EG, Navarro YG. 2009. Hypoglycemic activity of constituents from Astianthus viminalis in normal and streptozotocin-induced diabetic mice. J Nat Med 63: 393-401.

9. Ikeda Y, Murakami A, Ohigashi H. 2008. Ursolic acid: An anti- and pro-inflammatory Triterpenoid. Mol Nutr Food Res 52: 26-42.

10. Ishikawa $T$, dos Santos Donatini R, Diaz IE, Yoshida M, Bacchi EM, Kato ET. 2008. Evaluation of gastroprotective activity of Plinia edulis (Vell.) Sobral (Myrtaceae) leaves in rats. J Ethnopharmacol 118: 527-529.

11. Jäger S, Trojan H, Kopp T, Laszczyk MN, Scheffler A. 2009. Pentacyclic Triterpene Distribution in Various Plants - Rich Sources for a New Group of Multi-Potent Plant Extracts. Molecules 14: 20162031.

12. Jin YR, Jin JL, Li CH, Piao XX, Jin NG. 2012. Ursolic acid enhances mouse liver regeneration after partial hepatectomy. Pharm Biol 50:523-528.

13. Kaur G, Jabbar Z, Athar M, Alam MS. 2006. Punica granatum (pomegranate) flower extract possesses potent antioxidant activity and abrogates Fe-NTA induced hepatotoxicity in mice. Food Chem Toxicol 44: 984-993.

14. Kong L, Li S, Liao Q, Zhang Y, Sun R, Zhu X, Zhang Q, Wang J, Wu X, Fang X, Zhu Y. 2013. Oleanolic acid and ursolic acid: novel hepatitis $\mathrm{C}$ 
virus antivirals that inhibit NS5B activity. Antivir Res 98: 44-53.

15. Kurek A, Nadkowska P, Pliszka S, Wolska KI. 2012. Modulation of antibiotic resistance in bacterial pathogens by oleanolic acid and ursolic acid. Phytomedicine 19: 515-519.

16. Mandal V, Mandal SC. 2010. Design and performance evaluation of a microwave based low carbon yielding extraction technique for naturally occurring bioactive triterpenoid: oleanolic acid. Biochem Eng J 5: 63-70.

17. Maurya A, Srivastava SK. 2012. Determination of Ursolic Acid and Ursolic Acid Lactone in the Leaves of Eucalyptus tereticornis by HPLC. J Brazil Chem Soc 23: 468-472.

18. Mirjalili SA. 2015. A Review on Biochemical Constituents and Medicinal Properties of Pomegranate (Punica granatum L.). J Med Plants 4: 1-22(in Persian).

19. Rao VS, de Melo CL, Queiroz MG, Lemos TL, Menezes DB, Melo TS, Santos FA. 2011. Ursolic Acid, a Pentacyclic Triterpene from Sambucus australis, Prevents Abdominal Adiposity in Mice Fed a High-Fat Diet. J Med Food 14: 1375-1382.

20. Saaby L, Jäger AK, Moesby L, Hansen EW, Christensen SB. 2011. Isolation of immunomodulatory triterpene acids from a standardized rose hip powder (Rosa canina L.). Phytother Res 25: 195-201.

21. Saravanan R, Viswanathan P, Pugalendi KV. 2006. Protective effect of ursolic acid on ethanol-mediated experimental liver damage in rats. Life Sci 78:713718.

22. Shanmugam MK, Dai X, Kumar AP, Tan BK, Sethi G, Bishayee A. 2013. Ursolic acid in cancer prevention and treatment: molecular targets, pharmacokinetics and clinical studies. Biochem Pharmacol 85:1579-1587.

23. Shao JW, Dai YC, Xue JP, Wang JC, Lin FP, Guo YH. 2011. In vitro and in vivo anticancer activity evaluation of ursolic acid derivatives. Eur J Med Chem 46: 2652-2661.
24. Suhagia BN, Rathod IS, Ezhava SB, Patel J. 2013. A Simple Method for the Isolation and Estimation of Ursolic acid in Alstonia Scholaris R. BR. Int J Pharmaceut Sci Res 4: 2807-2811.

25. Tehranifar A, Zarei M, Nemati Z, Esfandiyari B, Vazifeshenas MR. 2010.Investigation of physicochemical properties and antioxidant activity of twenty Iranian pomegranate (Punica granatum L.) cultivars. Sci Hortic 126: 180-185.

26. Tian S, Shi Y, Yu Q, Upur H. 2010. Determination of oleanolic acid and ursolic acid contents in Ziziphora clinopodioides Lam. by HPLC method. Pharmacogn Mag 6: 116-119.

27. Wang H, Wanga Z, Guob W. 2008. Comparative determination of ursolic acid and oleanolic acid of Macrocarpium officinalis (Sieb. et Zucc.) Nakai by RP-HPLC. Ind Crop Prod 28: 328-332.

28. Wu HY, Chang CI, Lin BW, Yu FL, Lin PY, Hsu JL, Yen CH, Liao MH, Shih WL. 2011. Suppression of hepatitis B virus $\mathrm{x}$ protein-mediated tumorigenic effects by ursolic Acid. J Agric Food Chem 59:1713-1722.

29. Xia EQ, Yu YY, Xu XR, Deng GF, Guo YJ, Li HB. 2011. Ultrasound-assisted extraction of oleanolic acid and ursolic acid from Ligustrum lucidum Ait. Ultrason Sonochem 19:772-776.

30. Xu XH, Su Q, Zang ZH. 2012. Simultaneous determination of oleanolic acid and ursolic acid by RP-HPLC in the leaves of Eriobotrya japonica Lindl. J Pharmaceut Anal 2: 238-240.

31. Yang YC, Wei MC, Hong SJ, Huang TC, Lee SZ. 2013. Development/optimization of a green procedure with ultrasound-assisted improved supercritical carbon dioxide to produce extracts enriched in oleanolic acid and ursolic acid from Scutellaria barbata D. Don. Ind Crop Prod 49: 542 $-553$.

32. Zhang L, Fu Q, Zhang Y. 2011. Composition of anthocyanins in pomegranate flowers and their antioxidant activity. Food Chem 127:1444-1449.

33. Zhang P, Cheng Y, Duan RD. 2013. Ursolic acid inhibits acid sphingomyelinase in intestinal cells. Phytother Res 27: 173-178. 